\title{
Small breed dogs with confirmed stroke: concurrent diseases and sonographic findings
}

\author{
[Acidente vascular cerebral em cães de raças pequenas: achados sonográficos \\ e doenças concomitantes] \\ C.F. Carvalho ${ }^{1,2}$, J.P. Andrade Neto ${ }^{3}$, S.A. Diniz $^{3}$ \\ ${ }^{1}$ UNICSUL - São Paulo, SP \\ ${ }^{2}$ Provet - Diagnóstico e Especialidades Veterinárias - São Paulo, SP \\ ${ }^{3}$ Veterinária autônoma
}

\begin{abstract}
Cerebrovascular accidents (CVA) are important causes of neurological clinical signs in dogs. The objective of this work was to describe concurrent diseases and ultrasonographic features in dogs with CVA confirmed through postmortem evaluation. All medical records of transcranial Doppler ultrasonography (TCDUS) examinations performed in 512 dogs between 2007 and 2009 were reviewed, searching for history and clinical diagnosis, as well as sonographic and histological results. Forty-two dogs were selected, showing acute onset of clinical signs with no progressive focal cerebral dysfunction and diagnosis of cerebrovascular disease confirmed at necropsy. Concurrent diseases and conditions were: cerebral amyloid microangiopathy $(33 \%)$, endocrinopathies $(31 \%)$, coagulopathy (24\%), Schnauzer hyperlipemia $(7 \%)$ and unknown $(5 \%)$. The relation between sonography and histology results indicated $100 \%$ sensitivity and $90 \%$ specificity for focal lesion detection. A diffuse decrease in echogenicity was related to inflammatory diseases and/or edema with $62 \%$ sensitivity. A diffuse increase in echogenicity has $100 \%$ sensitivity and was usually related to aging changes. This study showed the occurrence of coexisting diseases with CVA and sonographic features of these conditions in small breed dogs.
\end{abstract}

Keywords: canine, ultrasonography, neurology, Doppler

\section{RESUMO}

O diagnóstico de acidente vascular cerebral (AVC) em cães é considerado importante causa de sinais clínicos neurológicos. Este trabalho objetivou descrever as doenças concomitantes e os aspectos sonográficos em cães com AVC confirmados por meio da avaliação post-mortem. Foram revisados os exames de ultrassonografia Doppler transcraniana (USDTC) realizados em 512 cães entre os anos de 2007 e 2009, pesquisando-se o histórico e o diagnóstico clínico, assim como os achados ultrassonográficos e histológicos. Destes, foram selecionados 42 cães que apresentavam sinais clínicos agudos de alteração cerebral focal não progressiva, e o diagnóstico de AVC foi confirmado na necropsia. As doenças e as condições clínicas concomitantes foram: microangiopatia amiloide cerebral (33\%), endocrinopatias (31\%), coagulopatias (24\%), hiperlipemia do Schnauzer (7\%) e inconclusivo (5\%). Relacionando-se os resultados ultrassonográficos e histológicos, observaram-se $100 \%$ de sensibilidade e 90\% de especificidade para a detecção de lesões focais. O diagnóstico de diminuição difusa da ecogenicidade foi relacionado a processos inflamatórios elou edema com $62 \%$ de sensibilidade. $O$ diagnóstico de aumento difuso da ecogenicidade apresentou $100 \%$ de sensibilidade e estava geralmente relacionado a alterações senis. Este estudo demonstrou a ocorrência de doenças coexistentes com o AVC e os aspectos ultrassonográficos destas condições em cães de raças pequenas.

Palavras-chave: cão, ultrassonografia, neurologia, Doppler

Recebido em 14 de abril de 2011

Aceito em 23 de maio de 2012

E-mail: cibelefcarvalho@gmail.com 


\section{INTRODUCTION}

Cerebrovascular diseases in dogs are defined as brain abnormalities caused by blood supply impairment (Joseph et al, 1987; Garosi, 2010). These diseases became clinically important because of the recognized impact in the cognitive, neurological and well-being areas of the dog. Previously considered uncommon, cerebrovascular disease is being recognized with greater frequency in veterinary medicine since

imaging techniques such as ultrasonography, computed tomography and magnetic resonance have become more readily available (Joseph $e t$ al., 1987). Stroke is currently one of the leading causes of human death (Joseph et al., 1987; Garosi, 2010) but its occurrence in dogs is not well known.

Stroke or cerebrovascular accident (CVA) is the most common clinical manifestation of cerebrovascular disease, and can be broadly divided into ischemic stroke and hemorrhagic stroke (Braund, 1994). Once the diagnosis of ischemic or hemorrhagic stroke is confirmed, potential underlying causes should be sought and treated accordingly.

The purpose of this study was to find the concurrent diseases and describe ultrasonography features of cerebrovascular diseases confirmed with postmortem examination in small breed dogs. This study was the first that compared sonographic and necropsy findings, describing concurrent clinical diseases in a high number of patients with histologically confirmed CVA.

\section{MATERIALS AND METHODS}

In order to describe clinical and sonographic features of CVA in dogs, a retrospective review of medical records of transcranial Doppler sonography (TCDS) examinations performed between 2007 and 2009 in 512 dogs with clinical signs of central nervous system disease was done. Forty-two patients were selected, all of which were small breed dogs with no predilection for sex, showing an acute onset of clinical signs (nystagmus, head tilt, hemiparesis, sudden blindness) with no progressive focal cerebral dysfunction and confirmed diagnosis of cerebrovascular disease at postmortem examinations within 30 days after imaging studies.

The TCDS examinations were performed by a single experienced operator. A micro-convex array probe and imaging frequencies ranging from 2-5 MHz were used. Dogs were restrained by the owners and placed into lateral or sternal recumbent positions without sedation. Hair clipping wasn't often required. Acoustic coupling gel was applied.

A fontanelle window was used, when available, to provide transverse and sagittal plane images. Transtemporal approaches were used in all dogs as acoustic windows to provide images of the dorsal and oblique dorsal planes. A suboccipital window was also used in all patients providing sagittal and transverse planes. Initially, gray scale images were taken. The goal of this initial survey was to evaluate the brain parenchyma anatomy by searching for abnormal increases or decreases (focal or diffuse lesions) in echogenicity in all the parenchyma. It was classified as normal echogenicity when the thalamus was less echogenic than the white matter (Hudson et al., 1989). Ventricular width and encephalic mantle thickness were measured. The normal B-mode parameters used in this study have been described in previous literature (Hudson et al., 1989; Hudson et al., 1990; Spaulding and Sharp, 1990; Hudson et al., 1991).

Color Doppler imaging (CDI) was performed to identify the cerebral arterial circle. Using CDI as a guide, the cerebral arteries of our interest (the rostral, middle and caudal cerebral arteries of both the left and the right hemispheres) were identified. The vessels of the arterial circle were considered normal when observed with minimum adjustment of Doppler color gain settings, without aliasing. Special attention was given to obtaining a correct insonation angle to maximize the Doppler signal, as described in technical reports in previous literature literature (Hudson et al., 1997; Fukushima et al., 1999; Seo et al., 2005; Carvalho et al., 2009; Duque et al., 2009). Once the vessels were identified, the pulsed wave Doppler was initiated, and a spectral tracing with three similar sequential waveforms was collected. Measurements were made on a representative spectral waveform to determine peak systolic velocity (PSV), end diastolic velocity (EDV). Resistive index (RI) was 
automatically calculated by the equipment. Normal spectral Doppler parameters used in this study have been described in previous literature (Duque et al., 2009).

Statistical analyses were performed using a statistical computer program to determine the distribution of frequency of all data obtained (sexual distribution, age, breed, type of lesions, diseases). Sonography results were compared with necropsy findings and agreement between the findings by Kappa analysis (K) with the following interpretation was calculated: values $<0.2$ indicated slight agreement, values between 0.2 and 0.4 indicated fair agreement, values between 0.4 and 0.6 indicated moderate agreement, values between 0.6 and 0.8 indicated substantial agreement and values between 0.8 and 1.0 indicated almost perfect agreement. Also specificity, sensibility, positive predictive value and negative predictive value of each data were calculated (Sardanelli and Di Leo, 2009).

\section{RESULTS}

Patients' records with confirmed CVA were evaluated to establish concurrent disorders with cerebrovascular diseases. Clinical factors were described (Table 1) and subdivided as follows: 1) cerebral amyloid microangiopathy $(33 \%)$; 2) endocrinopathies $(31 \%)$ such as diabetes mellitus, hyperadrenocorticism and hypothyroidism; 3) coagulopathy (24\%); 4) Schnauzer hyperlipemia $(7 \%) ; 5)$ unknown $(5 \%)$.

Table 1. Distribution of concurrent diseases with confirmed cerebrovascular accident (CVA) in 42 dogs examined through ultrasonography between August 2007 and June 2009

\begin{tabular}{lccc}
\hline Concurrent diseases & $\begin{array}{c}\text { Number of } \\
\text { patients }\end{array}$ & $\begin{array}{c}\text { Percentage of } \\
\text { patients }(\%)\end{array}$ & $\begin{array}{c}\text { Stroke's } \\
\text { classification }\end{array}$ \\
\hline Diabetes mellitus & 05 & 12 & Ischemic \\
Diabetes and hyperadrenocorticism & 01 & 2,5 & Ischemic \\
Hyperadrenocorticism & 06 & 14 & Ischemic \\
Hypothyroidism & 01 & 2,5 & Ischemic \\
Hyperlipemia & 03 & 7 & Ischemic \\
Cerebral amyloid micro angiopathy & 14 & 33 & Ischemic (02) \\
hemorrhagic (12) \\
Hemoparasites & 08 & 19 & hemorrhagic \\
Coagulation disorders (others than hemoparasites) & 02 & 5 & Ischemic \\
Unknown & 02 & 5 & Hemorrhagic \\
Total & 42 & 100 & \\
\hline
\end{tabular}

Results showed that there was no sexual predilection in canine cerebrovascular disease ( $52 \%$ male and $48 \%$ female), but older dogs were more often affected, with a mean age of 9 years (range 15 months-18 years).

The B-mode results data were summarized and compared with postmortem findings. Transcranial sonography detected focal lesions in 22 dogs (100\% sensitivity, 90\% specificity, positive predictive value of $81 \%$ and negative predictive value of $100 \%$ ). Hyperechogenic focal lesions have $100 \%$ sensitivity, positive predictive value of $100 \%$ and negative predictive value of $10 \%$. Hypoechogenic focal lesions have $100 \%$ sensitivity, $33 \%$ specificity, positive predictive value of $25 \%$ and negative predictive value of $0 \%$.

Diffuse encephalic lesions were observed in 20 dogs $(87 \%$ sensitivity, $90 \%$ specificity, positive predictive value of $87 \%$ and negative predictive value of $89 \%$ ). Hyperechogenic diffuse lesions have $100 \%$ sensitivity, but no specificity $(0 \%)$, positive predictive value of $100 \%$ and no negative predictive value. Hypoechogenic diffuse lesions have $62 \%$ sensitivity, no specificity $(0 \%)$, positive predictive value of $100 \%$ and negative predictive value of $33 \%$. No abnormalities were found in 10 patients on Bmode scan, although these dogs presented abnormal Dopplervelocimetric values for one or more arteries studied. Duplex Doppler ultrasound findings detected were mainly related to changes in the RI and morphology of the wave. Higher RI values were detected in $33 \mathrm{dogs}$ and only 4 animals showed normal Doppler spectral parameters, with RI values ranging from 0.45 to 0.55 (Seo et al., 2005).

\section{DISCUSSION}

To discover the clinical disorders concurrent with CVA and describe sonographic features, all data 
were related with postmortem pathological findings. The stroke diagnosis is important; likewise the potential underlying clinical diseases in order to treat patients accordingly. Ischemic encephalopathy is defined as a focal or general interruption of blood flow in the brain parenchyma, resulting in neuronal lesion and transient or permanent neurological dysfunction (Hoerlein, 1987; Guyton and Hall, 2000). Focal cerebral ischemia may occur after critical vascular changes that decrease blood flow velocity in any portion of the brain. Ischemic stroke results from occlusion of a cerebral blood vessel by a thrombus or embolism, depriving the brain of oxygen and glucose. Underlying causes of global cerebral ischemia include severe hypotension, chronic lung diseases, cardiac stop; increased wall vessel permeability and changes of blood viscosity promoting diffuse cerebral edema and finally anesthesia "accidents" with decreased brain oxygenation (Braund, 1994). Whereas hemorrhagic stroke results from rupture of a blood vessel wall within the brain parenchyma or subarachnoid space (Pattersen et al., 1985; Swayne et al., 1988; Braund, 1994). Our study showed at necropsy 22 cases classified as hemorrhagic and 20 as ischemic strokes.

Our results showed that on B-mode scanning there were much more focal lesions than diffuse ones and hyperechoic changes are the most frequently found. Hemorrhagic disorders of brain parenchyma usually presented hyperechogenic (Burgin et al., 2000; Carvalho et al., 2007; Carvalho et al., 2009). Our research demonstrated that the sonographic detection of focal lesions is sensitive, mainly with hyperechoic ones. The relation between ultrasonography and histology results indicated that hyperechoic focal lesions detected were associated with several causes including hemorrhagic mass and degenerative disorders. A study suggests that prolonged systemic stress in brain parenchyma, induced by several conditions, may be related to amyloid apposition in dogs. This protein is highly dense and can be widely distributed in the brain of elderly dogs (Yoshino et al., 1996). This could be a reason for the hyperechoic lesion findings in aged dogs. Diffuse decrease in echogenicity has low sensibility but it was related to few conditions, such as edema. Diffuse increased echogenicity was related to aging changes and patients with endocrinopathies. There are no studies describing sonographic aging changes in dog brains. Brain degenerative disorders in dogs are a recent field of research, and it seems that amyloid plaque deposition may be formed as a result of the degeneration of capillaries with their consequent fragility (Yoshino et al., 1996). But, in fact, endocrinopathies generally leads to changes in cholesterol metabolism (Pattersen et al., 1985), and this could explain why these patients use to have hemodynamic changes secondary to vascular stenosis, which promotes a chronic hypoxia as occurs in humans.

Hyperechoic focal lesions were correlated to local artery hemodynamic changes. RI was increased in one or more vessels in 28 animals and in 09 animals no Dopplervelocimetric changes were observed. It is known that hemorrhagic areas may also cause mass effect on adjacent vessels, and tumors or other conditions could lead to vascular stenosis (Burgin et al., 2000). Doppler spectral mapping of cerebrovascular stenosis can be recognized by changes in waveform (Nagai et al., 1997). The brain has efficient compensatory hemodynamic mechanisms that maintain normal intracranial pressure and RI (Guyton and Hall, 2000), but the waveform of the affected vessel may be compromised in the correspondent territory (Nagai et al., 1997). Although the deposition of atheromatous plaques does not happen naturally in the aging process of the dog, it is known that animals which have diseases that lead to changes in cholesterol metabolism may have vascular stenosis similar to that which occurs in humans (Pattersen et al., 1985; Joseph et al, 1987; Braund, 1994; Garosi, 2010). These promote vascular stenosis in several degrees (Burgin et al., 2000) and can be detected by Doppler spectral (Nagai et al., 1997; Fukushima et al., 2000; Saito et al., 2003; Carvalho et al., 2007; Carvalho et al., 2010a; Carvalho et al., 2010b).).

Regarding sexual distribution found in this study, besides the underlying causes of stroke, the results demonstrated that there is no sexual predisposition, and were in accordance with veterinary literature (Garosi, 2010). Breed distribution demonstrated that miniature and standard poodles were the most prevalent. A few studies have suggested some breed predilection for stroke (Garosi, 2010). Schnauzer (all miniature types) was the third breed among the most involved in this study. This may be linked 
to the fact that these dogs presented a predisposition to hyperlipemia (Braund, 1994). Due to a gap in the literature, further studies are needed to correlate imaging with macroscopic and histological findings in dogs of different breeds affected by normal aging and cerebrovascular diseases.

Vascular encephalopathy was an unexpected finding in young dogs, which had no clinical history of endocrine disorders, inflammatory or infectious, or neoplasic diseases. In $19 \%$ the underlying cause was related to coagulation disorder and/or vasculitis by the presence of haemoparasites (Babesia sp and Erlichia sp). Because this study was conducted in a tropical country we must take into account the fact that the ectoparasitic infestations are a common problem. Thus, hemoparasitosis may be a cause of ischemic stroke to be considered in younger dogs (Figure 1). A major cause of ischemic stroke in humans is related to atheromatous deposition in cervical blood vessels. However, the dogs produce an alpha protein that reduces this risk (Pattersen et al., 1985; Swayne et al., 1988). In this study, cerebral amyloid microangiopathy (Figure 2) was the most concurrent disease in old dogs with CVA. It was related both to hemorrhagic and ischemic strokes. There are no studies describing the imaging of degenerative changes expected in normal elderly dogs or relating these diseases with CVA.

The presence of focal lesions and changes in Doppler parameters (Figure 3) showed substantial agreement $(\mathrm{k}=0.8 \mathrm{j} 1)$. A potential reason for this is that they may lead to stenosis of cerebral vessels promoting the development of hypoxic or ischemic areas in different degrees, but further studies are necessary to investigate hemodynamic patterns in these cases.

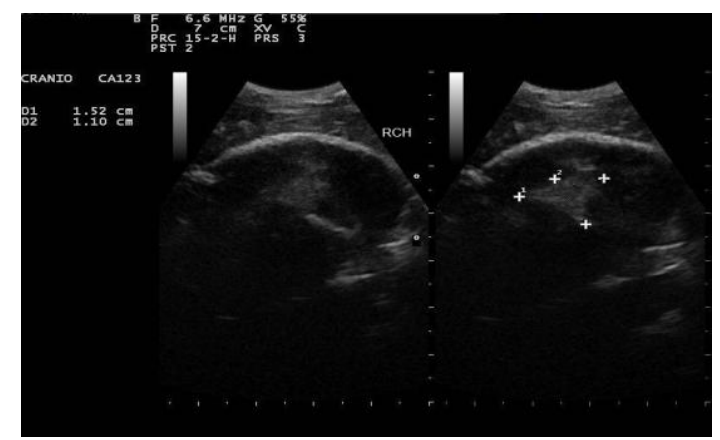

Figure 1. Transcranial ultrasonography: right temporal approach. Calipers (+) show hyperechoic focal lesion in right cerebral hemisphere $(\mathrm{RCH})$ in a dog with cerebrovascular accident concurrent with coagulopathy.

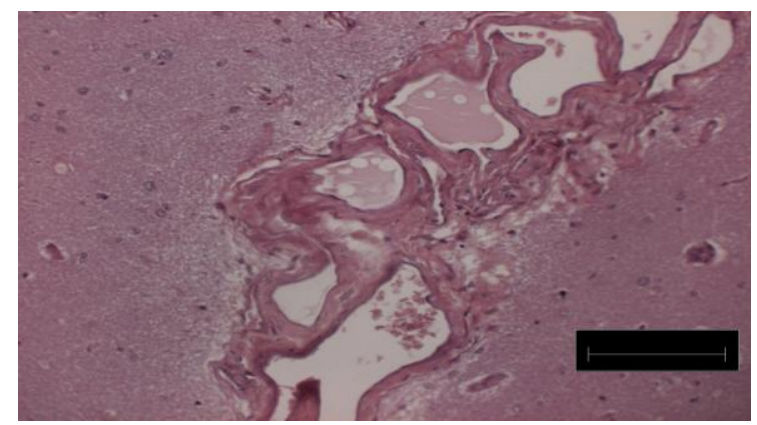

Figure 2. cerebral amyloid microangiopathy: thickness of blood vessels wall provided by amyloid apposition, in the cerebral cortex of a 12 year old dog (Congo red staining; magnification scale $100 \mu \mathrm{m})$. Photo by: Paulo C. Maiorka.

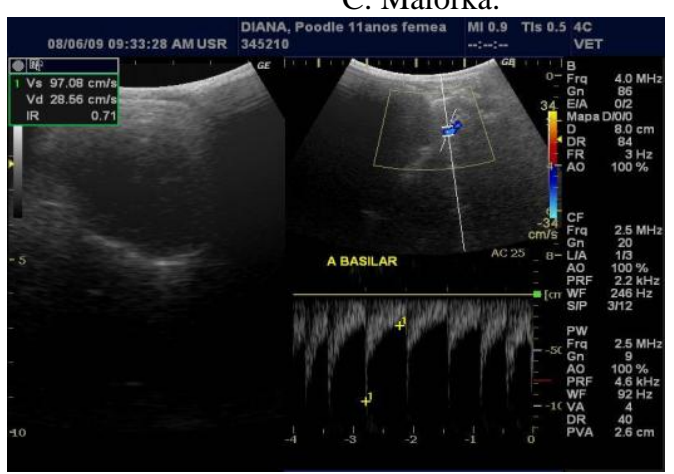

Figure 3. Transcranial Doppler ultrasonography in a dog: transocciptal approach, sagittal plane. Triplex Doppler mapping shows cerebral artery (basilar) with high systolic peaks. Vs = systolic peak velocity; $\mathrm{Vd}=$ diastolic peak velocity; $\mathrm{IR}=$ resistive index; $\mathrm{AC}=$ insonation angle. Photo: Cibele Figueira Carvalho. 
Underlying causes remain unknown in two patients $(5 \%)$ due to the absence of gross changes at necropsy. It is important to highlight that all patients included in this study were small breed dogs (up to $15 \mathrm{~kg}$ ) to avoid sound attenuation since bone limits sound transmission.

In summary, the results of this study provided information about ultrasonography features and concurrent diseases with CVA in small breed dogs. But further studies are needed in order to investigate whether TCDS could monitor the treatment of CVA or be a tool to prevent these events.

\section{ACKNOWLEDGEMENT}

Special thanks to Dr. Paulo C. Maiorka for helping with pathology findings and interpretations.

\section{REFERENCES}

BRAUND, KG. Clinical Syndromes in Veterinary Neurology. 2nd ed. St. Louis: Mosby - Year Book, 1994. p.113-114.

BURGIN, W.S.; MALKOFF, M.; FELBERG, R.A. et al. Transcranial Doppler ultrasound criteria for recanalization after trombolysis for middle artery stroke. Stroke, v.31, p.1128-1132, 2000.

CARVALHO, C.F.; ANDRADE NETO, J.P.; JIMENEZ, C.D. et al. Ultra-sonografia transcraniana em cães com distúrbios neurológicos de origem central. Arq. Bras. Med. Vet. Zootec., v.59, p.1412-1416, 2007.

CARVALHO, C.F.; DUPRÉ, A.S.A.; PEREZ, R.B. Ultrassom Doppler Transcraniano. In: CARVALHO, C.F. Ultrassonografia Doppler em pequenos animais. Roca: São Paulo, 2009. p.159-177.

CARVALHO, C.F.; ANDRADE NETO, J.P.; JIMENEZ, C.D. et al. Transcranial duplex Doppler ultrasonography of cerebral arteries in dogs with hydrocephalus. Arq. Bras. Med. Vet. Zootec., v.62, p.54-63, 2010a.

CARVALHO, C.F.; PEREZ, R.B.; CHAMMAS, M.C.; MAIORKA, P.C. Ultrasonographic findings of granulomatous meningoencephalitis in small breed dogs. Proc Annual Meeting of ECVDI. Giessen, Germany. 2010b.
DUQUE, F.J.; DOMINGUEZ-ROLDAN, J.M.; RUIZ, P. et al. Transcranial color-coded duplex sonography Vet. Radiol. Ultras., v.50, p.530-535, 2009.

FUKUSHIMA, U.; SASAKI, S.; OKANO, S. et al. The comparison between the cerebral blood flow directly measures and cerebral blood flow velocity in the middle and basilar cerebral arteries measured by transcranial Doppler ultrasonography. J. Vet. Med. Sci., v.61, p.12931297, 1999.

FUKUSHIMA, U.; MIYASHITA, K.; OKANO, S. et al. Evaluation of Intracranial Pressure by Transcranial Doppler Ultrasonography in Dogs with Intracranial Hypertension. J. Vet. Med. Sci., v.62, p.353-355, 2000.

GAROSI, L.S. Cerebrovascular disease in dogs and cats. Vet. Clin. North Am. Small Anim. Pract., v.40, p.65-79, 2010.

GUYTON, A.C.; HALL, J.E. Cerebral blood flow, the cerebrospinal fluid, and brain metabolism. In: SCHMITT, W. Textbook of medical physiology. 10nd ed., Philadelphia: WB Saunders, 2000. p.709-715.

HOERLEIN, B.F. Primary disorders of the central nervous system In: HOERLEIN, B.F. Canine neurology: Diagnosis and treatment. 3nd ed., Philadelphia: W.B. Sauders, 1987. p.340342.

HUDSON, J.A.; CARTEE, R.E.; SIMPSON, S.T. et al. Ultrasonographic anatomy of the canine brain. Vet. Radiol., v.30, p.13-21, 1989.

HUDSON, J.A.; SIMPSON, S.T.; BUXTON, D.F. et al. Ultrasonographic diagnosis of canine hydrocephalus. Vet. Radiol. Ultrasound., v.31, p.50-58, 1990.

HUDSON, J.A.; SIMPSON, S.T.; COX, N.R. et al. Ultrasonographic examination of the normal canine neonatal brain Vet. Radiol. Ultrasound., v.32, p.50-59, 1991.

HUDSON, J.A.; BUXTON, D.F.; COX, N.R. Color flow Doppler imaging and Doppler spectral analysis of the brain of neonatal dogs. Vet. Radiol. Ultrasound., v.38, p.313-322, 1997.

JOSEPH, R.J.; GRENLEE, P.G.; CARRILO, J.M.; KAY, W.J. Canine cerebrovascular disease: Clinical and pathological findings in 17 cases. J. Am. Anim. Hosp. Assoc., v.24, p.569576, 1987. 
NAGAI, H.; MORITAKE, K.; TAKAYA, M. Correlation between Transcranial Doppler ultrasonography and regional cerebral blood flow in experimental intracranial hypertension. Stroke, v.28, p.603-608, 1997.

PATTERSEN, J.S.; RUSLEY, M.S.; ZACHARY, J.F. Neurologic manifestations of cerebrovascular atherosclerosis associated with primary hypothyroidism in dog. J. Am. Anim. Hosp. Assoc., v.186, p.499-503, 1985.

SARDANELLI, F; Di LEO, G. Biostatistic for Radiologists - planning, performing and writing a radiologic study. Italy:Springer, 2009. 219p.

SAITO, M.; OLBY, N.J.; SPAULDING, K. et al. Relationship among basilar artery resistance index, degree of ventriculomegaly, and clinical signs in hydrocephalic dogs. Vet. Radiol. Ultrasound., v.44, p.687-694, 2003.
SEO, M.; CHOI, H.; LEE, K. et al. Transcranial Doppler ultrasound analysis of resistive index in rostral and caudal cerebral arteries in dogs. $J$. Vet. Sci., v.6, p.61-66, 2005.

SPAULDING, K.A.; SHARP, N.J.H. Ultrasonographic imaging of the lateral cerebral ventricles in the dog. Vet. Radiol., v.31, p.59-64, 1990.

SWAYNE, D.E.; TYLER, D.E.; BARKER, J. Cerebral infarction with associated venous thrombosis in dogs. Vet. Pathol., v.25, p.371320, 1988.

YOSHINO, T.; UCHIDA, K.; TATEYAMA, S. et al. A retrospective study of canine senile plaques and cerebral amyloid angiopathy. Vet. Pathol., v.33, p.230-234, 1996. 